\title{
Joint trajectories of life style indicators and their links to psychopathological outcomes in the adolescence
}

\author{
Anhui Zhang ${ }^{1}$, Jiao Fang ${ }^{2}$, Yuhui Wan ${ }^{2,3}$, Puyu Su ${ }^{2,3}$, Fangbiao Tao ${ }^{2,3}$ and Ying Sun ${ }^{2,3^{*}}$ (D)
}

\begin{abstract}
Background: Rapid socio-economic development makes China a unique laboratory for examining how lifestyle changes affect adolescent mental health. This study aims to identify joint trajectories of modifiable lifestyle indicators during pubertal transition and its associations with psychopathological outcomes.

Methods: A cohort of 1974 children aged 7-9 years were recruited in Anhui Province, China during March 2013. The assessment of lifestyle behaviors (screen time, physical activity, sleep duration and beverage intake) and depressive symptoms were conducted from Wave 1 to Wave 4 (2018). Suicide ideation, non-suicidal self-harm (NSSI) and alcohol use were self-reported at Wave 4. Longitudinal trajectories of lifestyle patterns were defined using group-based multi-trajectory models in 2019.
\end{abstract}

Results: Four lifestyle trajectories were identified: persistent healthy (39.9\%), suboptimal healthy (25.3\%), unhealthy mitigation (17.2\%), and persistent unhealthy (17.7\%). Compared with persistent healthy group, the risk of subsequent suicide ideation [odds ratio (OR): $2.86,95 \% \mathrm{Cl}: 2.15-3.81$ ], depressive symptoms (OR: $2.16,95 \% \mathrm{Cl}$ : 1.393.35), alcohol use (OR: 2.53, 95\%Cl: 1.78-3.61) and non-suicidal self-harm (OR: 1.35, 95\%Cl: 1.09-1.67) was significantly higher in persistent unhealthy group.

Conclusions: This study provided convincing evidence that unhealthy lifestyle trajectory during adolescence is associated with more than two-fold elevated odds for multiple domains of psychopathological outcomes over 5 years.

Keywords: Lifestyle pattern, Longitudinal trajectory, Psychopathology, Pubertal transition

\section{Background}

The past three decades brought tremendous changing in the socio-economic context of adolescent development in China with implications for mental health. China is heading towards a ballooning epidemic of mental health problems in teens $[1,2]$. The nationwide psychiatric survey among 73,992 participants aged 6-16 years of age in

\footnotetext{
* Correspondence: sy54@yeah.net

2Department of Maternal, Child \& Adolescent Health, School of Public Health, Anhui Medical University, Hefei 230032, Anhui Province, China

${ }^{3}$ MOE Key Laboratory of Population Health Across Life Cycle, Hefei 230032, Anhui Province, China

Full list of author information is available at the end of the article
}

China suggests that the weighted prevalence of any disorder was $17.5 \%$ [3]. The 12-month prevalence of nonsuicidal self-injury (NSSI), suicidal ideation and suicide attempt was 26.1, 17.5 and $4.4 \%$, respectively, based on a population of 14,820 students aged 10-20 years from three provinces in China [1].

Such soaring of mental health problem has paralleled a dramatic shift in health-related behaviors and lifestyle from traditional, healthy patterns towards unhealthy patterns. During the transition from childhood to adolescence, children in China gradually develop its unique lifestyle pattern due to high level academic pressure

(c) The Author(s). 2021 Open Access This article is licensed under a Creative Commons Attribution 4.0 International License, which permits use, sharing, adaptation, distribution and reproduction in any medium or format, as long as you give appropriate credit to the original author(s) and the source, provide a link to the Creative Commons licence, and indicate if changes were made. The images or other third party material in this article are included in the article's Creative Commons licence, unless indicated otherwise in a credit line to the material. If material is not included in the article's Creative Commons licence and your intended use is not permitted by statutory regulation or exceeds the permitted use, you will need to obtain permission directly from the copyright holder. To view a copy of this licence, visit http://creativecommons.org/licenses/by/4.0/ The Creative Commons Public Domain Dedication waiver (http://creativecommons.org/publicdomain/zero/1.0/) applies to the data made available in this article, unless otherwise stated in a credit line to the data. 
compared with their counterparts in western countries, including prolonged sitting and screen time $[4,5]$, high proportion of regular sugar-sweetened beverages (SSBs) consumption [6] and insufficient sleep [7].

The role of lifestyle in the causation of mental health has long been established and provoked recommendations regarding diet, sedentary activity (primarily screen time), physical activity (PA), and sleep [8]. Recent metaanalyses of prospective studies also concluded inverse associations of PA with depression in youth [9] and children [10]. Our previous work explored the potential importance of eating patterns for mental health in 14,500 adolescents at grade 7-12 from 32 schools in 4 provinces across China [11], and found a significant doseresponse relationship between SSBs consumption pattern with higher risk of psychological symptoms during adolescence. A recent population-based cohort study in Norway, Trondheim Early Secure Study, reported an association between short sleep duration and increased risk of future incidence of emotional disorder symptoms in both boys and girls and between reduced sleep and behavioral disorder symptoms in boys [12].

Previous studies have demonstrated that adolescents are more likely to engage in a spectrum of lifestyle risk behaviours, such as high sugar-sweetened beveages consumption, being physically inactive, engaging in sedentary behaviour and excessive screen time, which may have synergistic effects on health $[13,14]$. The majority of studies focused on individual behavior [15] or summed multiple behaviors into an index score, e. g. a lifestyle risk index [7].

Adolescents establish patterns of behavior and make lifestyle choices that affect both their current and future health and well-being $[16,17]$. The onset of adolescence represents an important turning point in an individual's life, not only from a psychological point of view, but also with regard to the emergence of psychopathology [18]. Given the importance of this transitional period and the need for targeted preventive efforts, as well as the high prevalence of depressive symptoms, non-suicidal selfinjury and suicide behaviors among Chinese children and adolescents $[1,3]$, the aim of this longitudinal study was to gather information on developmental trajectory of a combination of modifiable, health-related behaviors among Chinese children over the transition to adolescence, and to evaluate their associations with selfdestructive behaviors (non-suicidal self-harm, suicide ideation) and depressive symptoms.

\section{Methods}

\section{Study design and participants}

The present study used data of an ongoing longitudinal study examining psychosocial determinants of growth and development in Anhui Province, China. As illustrated in Fig. 1, of a total of 2025 students in grade 1 to 3 from four large elementary schools of Bengbu city, 1974 (1104 boys, 55.9\%) agreed to participate. Bengbu city, located in north Anhui Province of China. The gross domestic product per capita (GDP) increased by over $12 \%$ annually, doubling the figure of the former period before 2010. It is one of the representative cities in China in terms of its urbanization and economic development.

Baseline survey started in March 2013, and subsequent waves of data collection took place 2 years (wave 2), 4 years (wave 3 ) and 5 years (wave 4 ) later. We secured approval from Institutional Review Boards at Anhui Medical University and then obtained written informed consent from parents and school teachers, as well as child assent. Parents of the students completed baseline questionnaire survey at home. In subsequent waves, questionnaires were completed by students in class at school with supervising research assistants available to answer questions following a standard script.

This study was approved by the Medical Ethics Committee of Anhui Medical University. All the study participants and their guardians provided written informed consent. All the methods in this study were in accordance with the institutional research committee and tenets of the Declaration of Helsinki.

\section{Measurements \\ Lifestyle factors}

Physical activity Youth physical activity levels were ascertained from the Youth Risk Behavior Survey 2013 (YRBS) at each wave [19]. Parents (wave 1) and adolescents (wave 2-wave 4) were asked "During the past 7 days, on how many days were your child (you) physically active for a total of at least 60 minutes per day? (Add up all the time you spent in any kind of physical activity that increased your heart rate and made you breathe hard some of the time.)".

Screen time Weekly average screen time was derived based on daily time (hours) spent on screen during weekdays and weekends (including watching television/ video, playing computer, iPad and smartphone), which was calculated as: weekly average screen time $=$ (weekday screen time $\times 5+$ weekend screen time $\times 2) / 7$.

Sugar-sweetened beverage consumption (SSBs) Sugar-sweetened beverage consumption was assessed though the question 'During the past 7 days, how many times did your child (you) drink at least 1 serving regular sugar-sweetened sodas, fruit drink, sweetened iced tea, sports /energy drink that contains sugar?' 


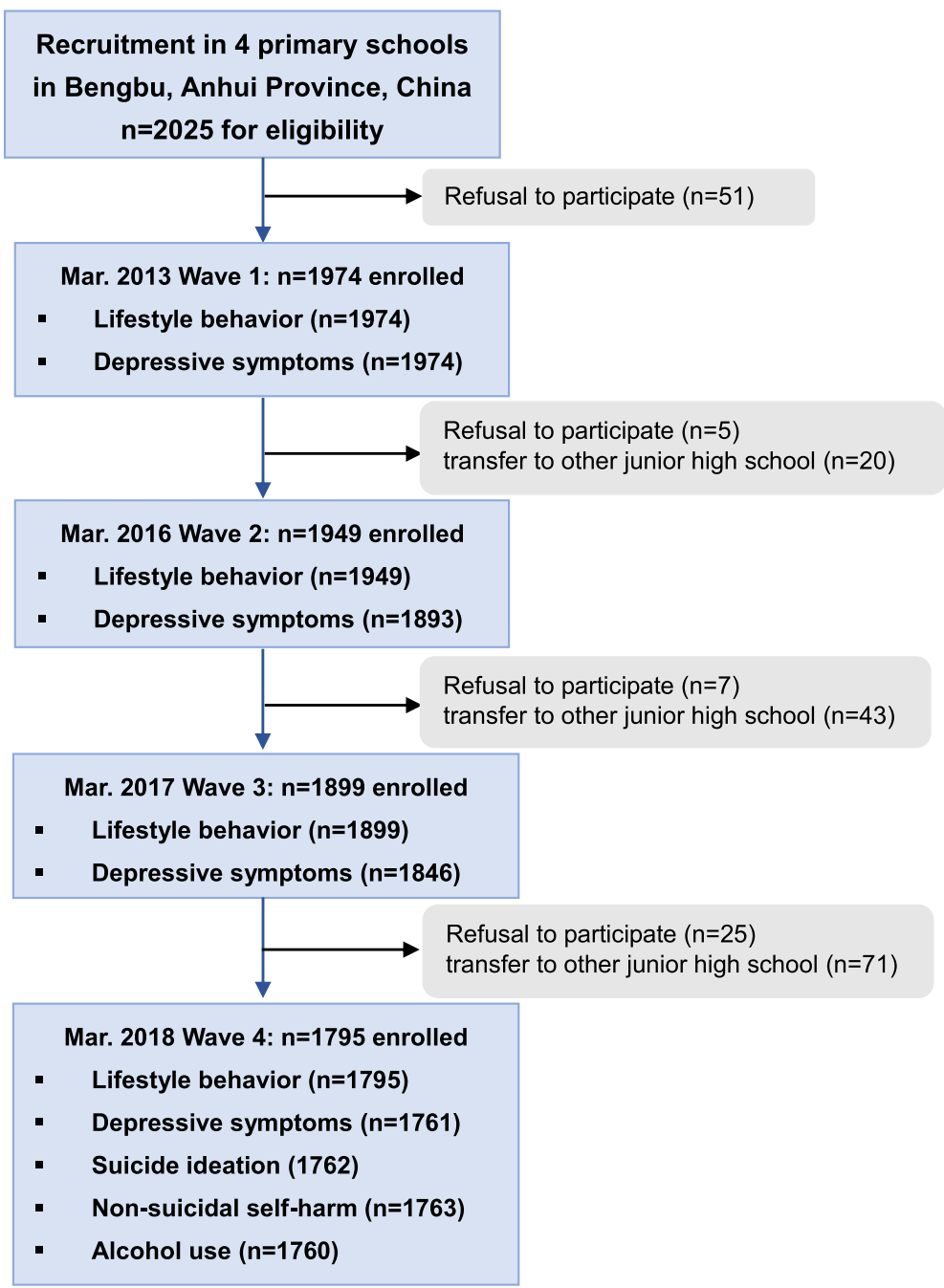

Fig. 1 Flowchart of Participants Follow-up

Sleep duration Sleep duration was estimated by subtracting self-reported waketime from bedtime, assessed by asking, "On a usual weekday this past week, when did your child (you) go to bed at night?" and "On a usual weekday this past week, when did your child (you) wake up the next morning?" Average sleep duration was calculated as: average sleep duration $=($ weekday sleep duration $\times 5+$ weekend sleep duration $\times 2) / 7$.

\section{Outcomes}

Baseline depressive symptoms assessment The Short Mood and Feelings Questionnaire Parent-report (SMFQ-P) has been widely used in children aged 6 to 17 years, including our previous work [20-22]. Cronbach's alphas for our sample were high (0.85). Scores on SMFQ-P range from 0 to 26 , we defined depressive symptoms as having an SMFQ-P score of 11 or greater [22].

Follow-up depressive symptoms assessment Self-reported depressive symptoms over the past 2 weeks were assessed by means of the Mood and Feelings Questionnaire (MFQ) at wave 2-4 [23]. The MFQ has shown prognostic validity in clinic and non-clinic samples [24], yielding high internal consistency $(\alpha=0.91-0.93)$ in the present sample. MFQ scores range from 0 to 66 , adolescents with total scores of 29 or above was considered depressive [25]. The split-half reliability was 0.90 , the Cronbach $\alpha$ was 0.93 , and the test-retest reliability was 0.84 in Chinese children and adolescents [26].

Suicide ideation At wave 4 (2018), a single-item question was used to assess suicide ideation ("Have you ever seriously thought about killing yourself and, if so, have 
you had these thoughts in the past 12 months?") from the World Mental Health CIDI (WMH-CIDI) [27].

Non-suicidal self-harm behaviors At wave 4 (2018), adolescents were asked "Have you ever harmed yourself in a way that was deliberate, but not intended as a means to take your life in the last (reference period)?" [28]. A list of eight non-suicidal self-harm (NSSI) (hitting, pulling hair, banging head, pinching, scratching, biting, firing/burning, cutting) methods was then presented. The internal consistency reliability of NSSI was 0.780 in Chinese adolescents [29].

Alcohol use Alcohol use at wave 4 (2018) was defined as having at least one drink of beer, wine, or liquor (not just a sip or a taste of someone else's drink) during the past 30 days [30].

\section{Covariates}

Body mass index At each wave, height and weight was measured and body mass index (BMI) was calculated as weight (in $\mathrm{kg}$ ) divided by height squared (in $\mathrm{m}$ ).

Parental education and family monthly income Parents at baseline reported educational attainment during the consent process and family monthly income from "1" for "< 2000 RMB" (ca. 313 US\$) to " 5 " for "> 15,000 RMB” (ca. 2345 US\$).

Warm parenting All parents were questioned a 13-item scale adapted by Raudino et al. [31] from the Child Rearing Practices Report and the Parenting Scale. Cronbach's alpha in the current study was 0.91 . The warm parenting score ranges from $0 \sim 52$, with higher scores indicating a more supportive and nurturing parental relationship (parental warmth).

Adverse childhood experiences At wave 4 (2018), adolescents reported experiences with adverse events including abuse and neglect by using the 10-item Adverse Childhood Experiences Questionnaire - Short Form (ACES-SF) [32]. Eight items from this measure were included. A total score with higher values indicating greater experience of childhood adversity. Cronbach's alpha in the current study was 0.75 .

\section{Statistical analysis Descriptive}

The study sample was characterized using descriptive statistics and frequency distributions at baseline and across following three waves. Average level of four lifestyle behaviors over time were analyzed by three-way repeated measures analysis of variance (ANOVA) with time, sex, family income, maternal education, and weight status as factors. Multiple comparisons were assessed by Bonferroni post-hoc test.

\section{GBTM model selection}

Group-based multi-trajectory modeling, a generalization of univariate group-based trajectory modeling to multiple outcomes [33], was adopted to examine latent clusters of children with similar lifestyle trajectories across the four lifestyle behaviors: weekly screen time, physical activity, sleep duration, and SSBs consumption. For counting variables of 'physical activity for $1 \mathrm{~h} /$ day' and 'SSBs consumption', the zero-inflated Poisson (ZIP) model was used. For continuous variables of 'weekley screen time' and 'sleep duration', cencered normal model was used. The number of classes that best fit was selected based were identified based on the acceptability of the available fit-criteria indices (i.e., Bayesian Information Criterion [BIC], sample-size-adjusted BIC [SSABIC], Akaike Information Criterion, Supplementary Table 1), model parsimony, distinctiveness of temporal patterns via visual inspection and cluster size.

\section{Associations between multiple trajectories and psychopathological outcomes}

After the lifestyle multi-trajectory profiles were identified, preliminary analyses calculated descriptive statistics and tested lifestyle trajectory group differences in terms of depressive symptoms across four waves, as well as suicide ideation, alcohol use and non-suicidal self-harm assessed in Wave 4. We then examined associations between longitudinal changes in depressive symptoms and lifestyle trajectory groups using mixed-effects logistic growth modeling, controlled for time, age, sex, BMI, family monthly income, low maternal education, warm parenting score and childhood adverse experiences (these predictor variables are uncorrelated with each other based on collinearity analysis). Multiple logistic regression model was performed to examine association between suicide ideation, alcohol use and non-suicidal self-harm with four lifestyle trajectory groups. Linearity in the multivariable models were checked upon for continuous predictors. In these models, the four lifestyle trajectories were treated as nominal variables with the persistent healthy lifestyle class serving as the reference group. Analyses were performed using STATA Software Version 14 (College Station, TX: StataCorp LP; 2015). A $P$-value $<0.05$ was considered statistically significant.

\section{Results}

\section{General information}

Table 1 describes baseline characteristics of the 1974 children (mean age 8.1 years, SD 0.87 at baseline) were included. More than half (55.9\%) were male. Over one- 
Table 1 Descriptive Analysis of Lifestyle Measures across Four Waves among Chinese Children, Mean (SD)

\begin{tabular}{|c|c|c|c|c|}
\hline & Wave 1 & Wave 2 & Wave 3 & Wave 4 \\
\hline Participants, nm & 1974 & 1949 & 1899 & 1795 \\
\hline Boys & $1098(55.6)$ & $1078(55.3)$ & $1060(55.8)$ & $1001(55.8)$ \\
\hline \multicolumn{5}{|l|}{ Family monthly income } \\
\hline$<2000 \mathrm{RMB}$ & $80(4.1)$ & $79(4.1)$ & $76(4.0)$ & $74(4.1)$ \\
\hline 2000-5000 RMB & $1061(53.7)$ & $1053(54.0)$ & $1021(53.8)$ & $960(53.5)$ \\
\hline 5000-10,000 RMB & $633(32.1)$ & $621(32.0)$ & $611(32.2)$ & $581(32.4)$ \\
\hline 10,000-15,000 RMB & $151(7.6)$ & $148(7.6)$ & $145(7.6)$ & $138(7.7)$ \\
\hline$>15,000 \mathrm{RMB}$ & $49(2.5)$ & $48(2.5)$ & $46(2.4)$ & $42(2.3)$ \\
\hline \multicolumn{5}{|l|}{ Maternal education } \\
\hline$<$ high school & $463(23.5)$ & 459 (23.6) & $437(23.0)$ & 405 (22.6) \\
\hline high school & $972(49.2)$ & $957(49.1)$ & $937(49.3)$ & $900(50.1)$ \\
\hline bachelors/graduate & $539(27.3)$ & $533(27.3)$ & $525(27.6)$ & $490(27.3)$ \\
\hline Body mass index, $\mathrm{kg} / \mathrm{m}^{2}$ & $16.75 \pm 2.9$ & $19.79 \pm 3.7$ & $20.26 \pm 3.9$ & $20.93 \pm 4.0$ \\
\hline ST, h/d & $2.94(1.8)$ & $2.71(2.1)^{\S}$ & $2.17(1.9)^{\S}$ & $1.92(1.4)^{\S}$ \\
\hline$P A \geq 1 \mathrm{~h} / \mathrm{d}, \mathrm{d} / \mathrm{w}$ & $2.38(1.9)$ & $2.63(2.0)^{\ddagger}$ & $3.60(1.8)^{\S}$ & $3.52(1.7)^{\S}$ \\
\hline Sleep duration, $\mathrm{h}$ & $9.39(0.5)$ & $9.16(0.6)^{\S}$ & $8.53(0.7)^{\S}$ & $8.06(0.7)^{\S}$ \\
\hline$S S B s \geq 1$ serving, $d / w$ & $1.51(2.0)$ & $1.78(1.8)^{\S}$ & $2.55(1.9)^{\S}$ & - \\
\hline
\end{tabular}

Abbreviations: ST screen time, $P A$ physical activity, SSBs sugar-sweetened beverages $\dagger P<0.05 ; \ddagger P<0.01 ; \S P<0.001$

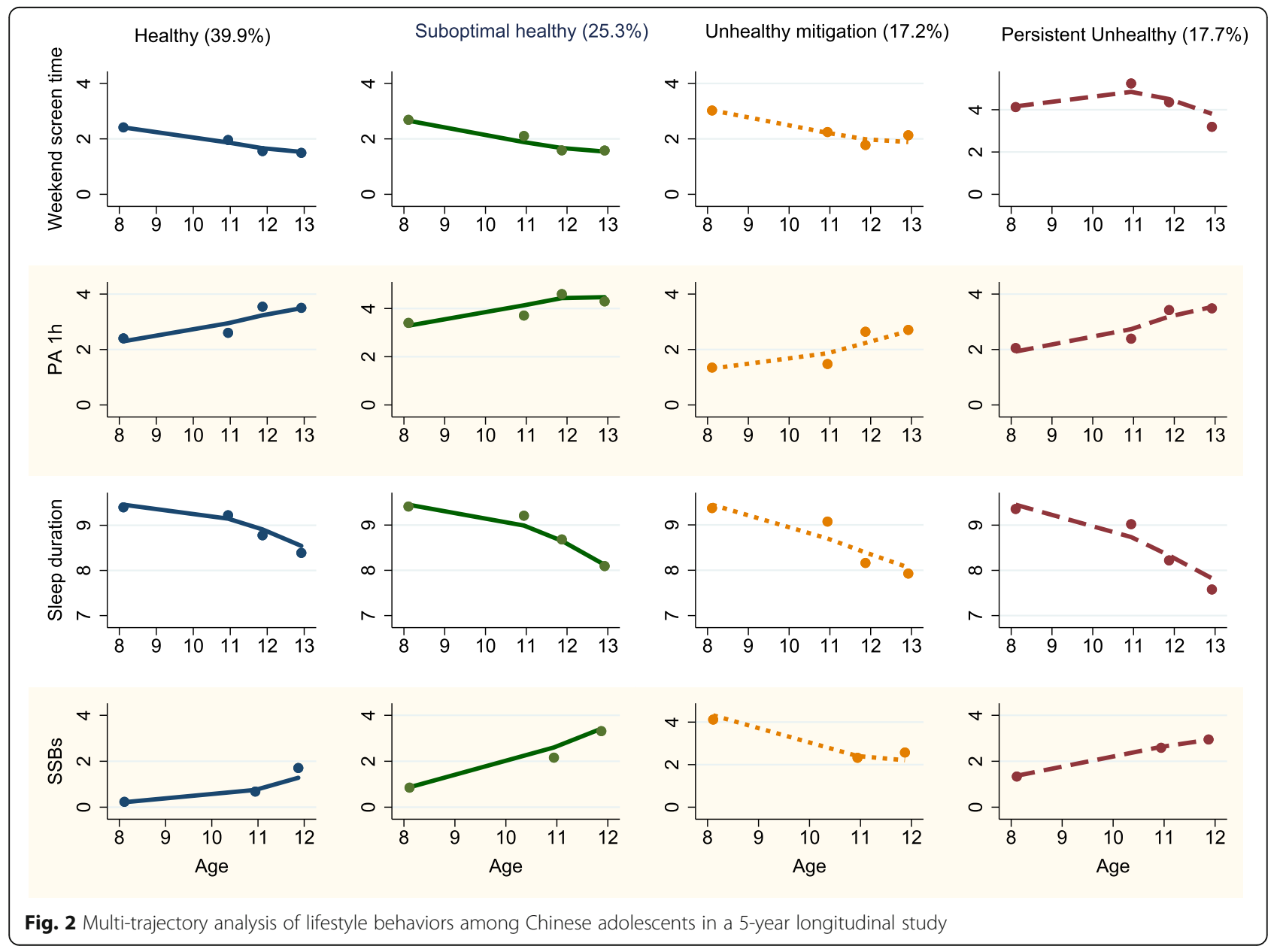


fourth of children at baseline were overweight (16.2\%) or obese $(12.4 \%)$. Less than $5 \%$ of the participants come from low-income families. Those who did not provide information on depressive symptoms, suicide ideation, NSSI and alcohol use had higher BMI and were older compared to those followed up. No significant differences were found in proportion of boys, baseline SMFQ score and family monthly income between missing and follow-up groups, except that boys were more likely have missing data on depressive symptoms in wave 2 (Appendix Table 2).

Group based multi-trajectory analysis of lifestyle patterns Multi-trajectory analysis of the longitudinal behavior data on 1974 children revealed four distinct trajectories of lifestyle patterns (model fit statistics see Appendix Table 1). Figure 2 showed the estimated mean levels in the four health-related behaviors at four waves for each trajectory group.

About 39.9\% (802/1974) of children maintained a stable-low level of screen time $(2.4 \mathrm{~h} / \mathrm{d}$ to $1.4 \mathrm{~h} / \mathrm{d}$, in wave 1 and wave 4 , respectively; the same hereinafter) and SSBs intake (0.2 times/wk. to 1.7 times/wk) with high-increasing physical activity (2.4 d/wk. to $3.5 \mathrm{~d} / \mathrm{wk})$, albeit the general decreasing trend in sleep duration $(9.4$ $\mathrm{h} / \mathrm{d}$ to $8.4 \mathrm{~h} / \mathrm{d}$ ), throughout the 5 -year follow-up (persistent healthy group).
More than one in four children (439/1974, 25.3\%) were classified as suboptimal healthy group who started with healthy behaviors, but then experienced a substantial increase in SSBs intake (0.8 times /wk. to 3.3 times/wk) and a slightly shorter sleep duration $(9.4 \mathrm{~h} / \mathrm{d}$ to $8.1 \mathrm{~h} / \mathrm{d})$;

Nearly $17.2 \%(332 / 1974)$ of children were classified as "unhealthy mitigation group", characterized with highdecreasing screen time $(3.0 \mathrm{~h} / \mathrm{d}$ to $2.1 \mathrm{~h} / \mathrm{d})$, lowincreasing physical activity $(1.3 \mathrm{~d} / \mathrm{wk}$. to $2.6 \mathrm{~d} / \mathrm{wk})$ and high-decreasing SSBs intake (4.4 times/wk. to 2.5 times /wk), albeit decreasing trend in sleep duration $(9.4 \mathrm{~h} / \mathrm{d}$ to $8.0 \mathrm{~h} / \mathrm{d}$ );

About 17.7\% (401/1974) of children were identified as "persistent unhealthy group", characterized with excessive screen time $(4.2 \mathrm{~h} / \mathrm{d}$ to $3.2 \mathrm{~h} / \mathrm{d})$, abrupt decrease in sleep duration $(9.4 \mathrm{~h} / \mathrm{d}$ to $7.5 \mathrm{~h} / \mathrm{d})$ and stable-high SSBs intake (1.3 times/wk. to 3.2 times/wk), albeit increasing physical activity $(2.0 \mathrm{~d} / \mathrm{wk}$. to $3.4 \mathrm{~d} / \mathrm{wk})$. The mean posterior probability for each trajectory group exceeded 0.92 , while other fit statistics also confirmed that the four latent trajectory groups were optimal for our study data.

\section{Association of four lifestyle trajectory groups with psychopathological outcomes}

Table 2 described the comparison of prevalence in depressive symptoms, suicide ideation, alcohol use and

Table 2 Prevalence of depressive symptoms, suicide ideation, alcohol use and non-suicidal self-harm across four lifestyle trajectory groups in the longitudinal lifestyle data on 1974 children

\begin{tabular}{|c|c|c|c|c|c|c|}
\hline \multirow[t]{2}{*}{ Outcomes } & \multirow[t]{2}{*}{ Participants } & \multirow{2}{*}{$\begin{array}{l}\text { Prevalence } \\
\text { n (\%) }\end{array}$} & \multicolumn{4}{|c|}{ Lifestyle Multi-trajectories ${ }^{a}$ [N (\%)] } \\
\hline & & & Healthy & Suboptimal Healthy & Unhealthy Mitigation & Unhealthy Persistent \\
\hline General & 1974 & & $787(39.9)$ & $499(25.3)$ & $339(17.2)$ & $349(17.7)$ \\
\hline Low maternal education ${ }^{b}$ & 1974 & & $156(19.5)$ & 95 (21.6) & $93(27.9)^{\S}$ & $119(29.7)^{\S}$ \\
\hline Low household income ${ }^{c}$ & 1974 & & $26(3.4)$ & $11(3.5)$ & $17(4.1)$ & $22(5.6)$ \\
\hline More than $1 \mathrm{ACE}$ & & & $206(28.8)$ & $130(32.8)$ & $115(39.4)^{\ddagger}$ & $148(41.3)^{\S}$ \\
\hline Warm parenting score $(0-15)$ & & & $11.3 \pm 3.7$ & $11.3 \pm 3.8$ & $10.5 \pm 4.1^{\ddagger}$ & $10.1 \pm 4.3^{\S}$ \\
\hline \multicolumn{7}{|l|}{ Depressive symptoms } \\
\hline Baseline & 1974 & $75(3.8)$ & $20(2.5)$ & $7(1.6)$ & $21(6.3)+$ & $27(6.7)+$ \\
\hline Wave 2 & 1893 & $116(6.1)$ & $29(3.8)$ & $13(3.1)$ & $17(5.4)$ & $57(14.5) \S$ \\
\hline Wave 3 & 1846 & $184(10.0)$ & $53(7.0)$ & $21(5.1)$ & $38(12.5) \dagger$ & $72(19.4) \S$ \\
\hline Wave 4 & 1761 & $230(13.1)$ & $67(9.3)$ & $32(8.1)$ & $55(18.8) \S$ & $86(21.3) \S$ \\
\hline Suicide ideation & 1762 & $191(10.8)$ & $50(7.1)$ & $39(8.6)$ & $41(13.8) \S$ & $61(19.9) \S$ \\
\hline Alcohol use & 1760 & $105(6.0)$ & $25(3.5)$ & $25(5.5)$ & $19(6.4)+$ & $36(11.8) \S$ \\
\hline Non-suicidal self-harm & 1763 & $403(22.9)$ & $138(19.5)$ & $103(22.7)$ & $68(22.8)$ & $94(30.7) \neq$ \\
\hline \multicolumn{7}{|l|}{ Missing } \\
\hline Wave 2 & 1749 & $25(1.3)$ & $12(1.5)$ & $7(1.4)$ & $4(1.2)$ & $2(0.6)$ \\
\hline Wave 3 & 1899 & $75(4.0)$ & $31(4.1)$ & $7(1.2)$ & $21(6.2)$ & $16(4.6)$ \\
\hline Wave 4 & 1795 & $179(9.1)$ & $73(9.3)$ & $30(6.0)$ & 37 (10.9) & $39(11.2)$ \\
\hline
\end{tabular}

${ }^{\mathrm{a}}$ Compared with healthy lifestyle persistent group, $+P<0.05 ; \neq P<0.01 ; \S P<0.001$

${ }^{b}$ Equal or lower than junior middle school;

'Household income equal or lower than 2000 yuan per month 
NSSI across trajectory groups. The prevalence of depressive symptoms across four waves was significantly higher in the unhealthy persistent group compared to both the persistent healthy and the suboptimal healthy groups (6.7\% vs. 2.5 and $1.6 \%$ at baseline, $P<0.05 ; 21.3 \%$ vs. 11.3 and $8.3 \%$ at wave $4, P<0.001)$.

Approximately 1 in 5 (19.9\%) children reported suicide ideation in the unhealthy persistent group, compared with 1 in $14(7.1 \%)$ in healthy group $(P<0.001)$. Alcohol use and NSSI were more frequent in the unhealthy persistent compared to the healthy groups $(11.8 \%$ vs. $3.5 \%$ for alcohol use, $P<0.001 ; 30.7 \%$ vs. $19.5 \%$ for NSSI, $P<$ $0.01)$.

A similar pattern was observed in the unhealthy mitigation group (Table 2). Depressive symptoms, suicide ideation and alcohol use over 5 years follow-up were significant higher compared with healthy groups $(18.8 \%$ vs. $9.3 \%$ for depressive symptoms, $P<0.001 ; 13.8 \%$ vs. $7.1 \%$ for suicide ideation, $P<0.001$; and $6.4 \%$ vs. $3.5 \%$ for alcohol use, $P<0.01$ ).

Similar attrition rates were observed across healthy, mitigation and persistent unhealthy lifestyle trajectories (Table 2).

\section{Prediction of psychopathological outcomes by the four distinct trajectory groups}

Multiple logistic regressions were used to present the association between the four lifestyle trajectory groups with suicide ideation (Appendix Table 3), alcohol use
(Appendix Table 4) and NSSI (Appendix Table 5), while logistic mixed effects model for depressive symptoms (Appendix Table 6), adjusted for time (for depressive only), age, BMI, sex, family income, low maternal education, warm parenting and adverse childhood experiences in Wave 4. "Unhealthy persistent" lifestyle trajectory was associated with an odds ratio (OR) of 2.86 (95\%CI, 2.15-3.81) for suicide ideation, 2.16 (95\%CI, 1.39-3.35) for depressive symptoms, 2.53 (95\%CI, 1.783.61) for alcohol use, and 1.35 (95\%CI, 1.09-1.67) for NSSI compared with children with healthy lifestyle trajectory (Fig. 3).

In addition, children in "unhealthy mitigation" trajectory also had a higher chance of suicide ideation [OR $(95 \% \mathrm{CI})=1.86(1.37-2.52)]$, and depressive symptoms $[\mathrm{OR}(95 \% \mathrm{CI})=1.96(1.23-3.12)]$ compared to the healthy group (Fig. 3).

Warm parenting were significantly associated with lower risk of psychopathological outcomes, while ACEs were significantly associated with higher risk of depressive symptoms (Appendix Table 6), suicide ideation (Appendix Table 3), and NSSI (Appendix Table 5).

\section{Discussion}

Using data from a cohort of children over the transition from childhood to adolescence, this is the first study to our knowledge to map and identify the developmental trajectories of multiple lifestyle factors, as well as its distinct relations with psychopathological outcomes over 5

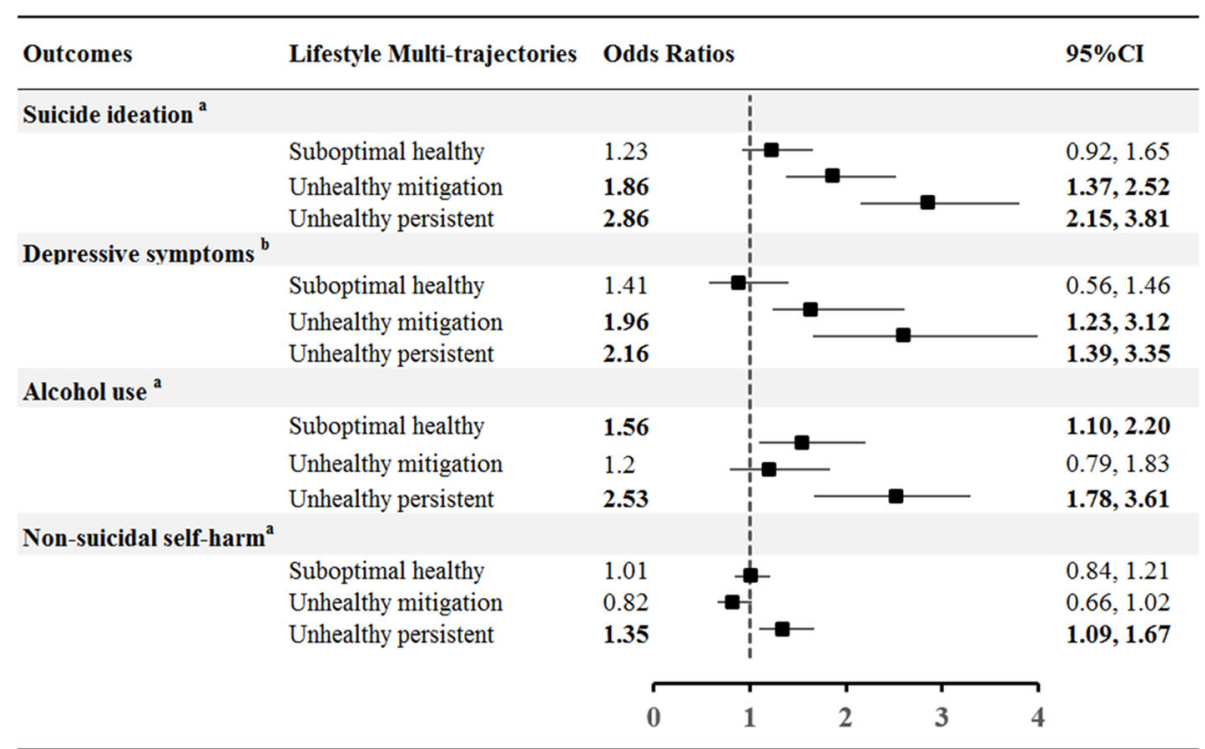

Fig. 3 Adjusted odds ratios with 95\% confidence intervals for suicide ideation, depressive symptoms, alcohol use and non-suicidal self-harm in different lifestyle trajectory groups. Bold numbers indicate significant differences when using the healthy group as the reference category; ${ }^{a}$ adjusted for depressive symptoms, age, BMI, sex, household income, maternal education, warm parenting and adverse childhood experiences in Wave 4, by using logistic regression models. ${ }^{b}$ adjusted for fixed effects of age, BMl, sex, household income, maternal education, warm parenting, and adverse childhood experiences in Wave 4 and random effects of individual and wave, by using mixed effects logistic regression models 
years of follow-up. Our findings identified that less than $40 \%$ of Chinese children belonged to a healthy lifestyle, and 1 in 5 were classified into a persistent unhealthy lifestyle combining stable-high screen time and SSBs intake with abrupt decrease in sleep duration (less than $8 \mathrm{~h} / \mathrm{d}$ ), which was independently associated with two-folds elevated odds for multiple domains of psychopathology, including suicide ideation, depressive symptoms, alcohol use, and non-suicidal self-harm.

The transition from childhood to adolescence has been seen as a crucial phase where unhealthy behaviors are adopted or discarded and tend to cluster as a result of changing roles and situations. In the 4-year longitudinal data of 389 children aged 10 and 14 years, Landsberg et al. identified three distinct lifestyle clusters: 'low activity and low-risk behaviour' cluster, 'high media time and high-risk behaviour' cluster and 'high activity and medium-risk behaviour' cluster [34]. To date, there are increasing investigations of longitudinal trajectories of multiple health behaviors in children and adolescents $[35,36]$. However, most of the longitudinal trajectory for variables of interest were analyzed for individual healthy behavior separately rather than jointly, potentially overestimating the effect of single health behaviors as unhealthy behaviors tend to cluster [37] particularly evident during adolescence. The virtue of the groupbased multi-trajectory modeling used in this study is that it highlights heterogeneity in the linkage between trajectories of multiple intrinsically relevant behaviors [33].

Evidence is accumulating on the mental health effects of modifiable lifestyle patterns among children and adolescents, however, most of these studies examined the association for specific behaviors. For example, researches showed that healthy lifestyle such as sufficient physical activity and sleep associated with a lower risk of youth suicidal ideation [38]. One recent meta-analysis from Korczak et al. [10] suggested that physical inactivity was associated with increased concurrent depressive symptoms; but the association with future depressive symptoms was weak due to a small number of longitudinal studies. Babic et al. [39] and others [40] found a clear inverse association between total recreational screen-time and computer use with psychological wellbeing. Results in the present study are in accordance previous findings, indicating the vulnerability for psychopathological outcomes during adolescence is associated with distinct trajectories of unhealthy lifestyle factors.

Our results that adolescents in "unhealthy mitigation group" showed similar risk for subsequent suicide ideation and depressive symptoms with those in "persistent unhealthy group", which was in line with Carli and his colleagues [36]. In their cross-sectional study of 12,395 adolescents from 11 European countries, the authors identified three groups of pupils, including high-risk group (13.2\%) who scored high on all risk behaviors and "invisible risk" group (29\%) who were positive for high screen time, sedentary behavior and reduced sleep. Results suggested that these two groups had similar prevalence of suicidal thoughts, subthreshold depression and depression. Children in the "unhealthy mitigation" group are characterized with high-decreasing screen time, lowincreasing physical activity and high-decreasing SSBs intake, suggesting developmental vulnerability may psychopathological vulnerability might be initially set by early childhood risky health-related behaviors, improvement in healthy lifestyle during adolescence are not adequate enough to mitigate the effects of existing risks. This population of children may represent an important "invisible" intervention target group for potentially reducing psychopathology and other untoward outcomes in adolescence.

It's interesting to note that children from the persistent unhealthy group reported stable-moderate level of physical activity, suggesting that greater vulnerability for psychopathology might have been associated with other potential risk factors, e.g. low parenting warmth and high adverse childhood experiences, as presented in this group of children. These findings indicate that parenting quality matters and may lower the risk of psychopathological outcomes and further suicide risk in adolescence for children with persistent unhealthy lifestyle.

The present study comprehensively assessed the associations between a combination of multiple repeatedlyassessed lifestyle behaviors and various psychopathological outcomes in Chinese children and adolescents. This study applied an innovative analytic approachgroup-based multi-trajectory analysis-that allows for the identification of diverse developmental trajectories of four lifestyle behaviors.

The contributions of this study should be viewed with its limitations in mind. First, data were collected through parent- or self-report with some single-item measures, which may have limited reliability and potentially cause misclassification. The lack of accelerometry-measured physical activity data limited our ability to capture the complexity of the physical activity and sedentary behavior patterns comprehensively. Accelerometer-derived measures of sleep and rest-activity patterns and use them to further understand the biology of sleep. Besides, the mix of parent-report in the first wave combined with adolescent report in later waves introduces instrumentation bias. Another limitation of this study is the reliance on self-reported of usual sleep hours to reflect an average of sleep durations. Future work should use multiple measures the characteristics of sleep quality, including objective measures. Thirdly shorter sleep length can also be regarded as one of the symptoms of depression (one of outcome variables), this partial correlation between 
these parameters might yield inflated correlations due to shared method variance. Fourthly, a small proportion of adolescents (10\%) missed questions related to psychopathological outcomes despite a similar demographic characteristics and baseline depressive symptoms compared with those included. Furthermore, this study has the inherent limitation of residual confounding due to unmeasured covariates, such as genetic background, which could make associations a poor estimate of causal effects. Finally, this study was conducted in one specific geographic region in China, and the findings may not be generalizable to adolescents across China.

\section{Conclusion}

This prospective cohort of Chinese children provides convincing epidemiological evidence that an unhealthy lifestyle during childhood was associated with more than two-fold elevated risk for suicide ideation, non-suicidal self-harm, depressive symptoms and alcohol use over a period of 5 years. This study provides a basis for quantitative estimates for the potential effect of a populationbased lifestyle intervention on the growing burden of mental disorders in China, especially among adolescents and emerging adults. Extended follow-up of this cohort would provide further evidence of the long-term impact of overall lifestyle modification in mental health promotion.

\section{Abbreviations}

PA: Physical activity; SSBs: Sugar-sweetened beverages

\section{Supplementary Information}

The online version contains supplementary material available at https://doi. org/10.1186/s12888-021-03403-y.

Additional file $\mathbf{1}$ Table $\mathbf{1}$. Model fit statistics of the group-based multitrajectory modeling for 2 - to 5 -class solutions. Table 2. Baseline characteristics of participants with missing data. Table 3. Multiple logistic regression models for suicide ideation and covariates in different lifestyle trajectory groups. Table 4. Multivariate logistic regression models for alcohol use and covariates in different lifestyle trajectory groups. Table $\mathbf{5}$. Multivariate logistic regression models for deliberate self-harm and covariates in different lifestyle trajectory groups. Table $\mathbf{6}$. Multivariate logistic regression models for depressive symptoms and covariates in different lifestyle trajectory groups.

\section{Acknowledgements}

The authors thank all the children and their parents in the study and the members of the survey teams.

\section{Authors' contributions}

YS and FB conceived the paper and were responsible for overall direction and planning. AZ, JF, YW and PS implemented the data collection and wrote the manuscript with input from all the authors. YW, PS, FT and YS provided oveall technical review and critical revision. All authors provided final approval for publication. The funding source did not play any role in designing the study or collecting, analyzing or interpreting the data or preparing this manuscript and deciding to submit the paper for publication.

\section{Funding}

This study was funded by grants from the National Natural Science Foundation of China (81673188 \& 81872638 for Y. Sun), Natural Science Foundation for Distinguished Young Scholars of Anhui Province (1908085 J26 for $Y$. Sun). The funders had no role in the design and conduct of the study; collection, management, analysis, and interpretation of the data, preparation, review, or approval of the manuscript.

Availability of data and materials

Data and materials of this study are available from the corresponding author upon reasonable request.

\section{Declarations}

Ethics approval and consent to participate

Ethical approval for this study was provided by the Institutional Review Board of the Anhui Medical University.

All data collection activities for this study were implemented with informed consent of participants.

Written informed consent was provided by the adolescent and his/her guardian, which is approved by Medical Ethics Committee of Anhui Medical University.

\section{Consent for publication}

Not applicable.

\section{Competing interests}

The authors declare that that they have no competing interests.

\section{Author details}

${ }^{1}$ Department of Child Health Care, Wuhu Maternal and Child Health (MCH) Center, Wuhu 230000, Anhui Province, China. ²Department of Maternal, Child \& Adolescent Health, School of Public Health, Anhui Medical University, Hefei 230032, Anhui Province, China. ${ }^{3}$ MOE Key Laboratory of Population Health Across Life Cycle, Hefei 230032, Anhui Province, China.

Received: 20 June 2020 Accepted: 31 July 2021

Published online: 17 August 2021

\section{References}

1. Wan Y, Chen R, Ma S, McFeeters D, Sun Y, Hao J, et al. Associations of adverse childhood experiences and social support with self-injurious behaviour and suicidality in adolescents. Br J Psychiatry. 2019;214(3):146-52. https://doi.org/10.1192/bjp.2018.263.

2. Zheng $Y$, Zheng XX. Current state and recent developments of child psychiatry in China. Child Adolesc Psychiatry Ment Health. 2015;9(1):10. https://doi.org/10.1186/s13034-015-0040-0.

3. Li F, Cui Y, Li Y, Guo L, Ke X, Liu J, et al. Prevalence of mental disorders in school children and adolescents in China: diagnostic data from detailed clinical assessments of 17,524 individuals. J Child Psychol Psychiatry. 2021 May 21. https://doi.org/10.1111/jcpp.13445.

4. Zhang QL, Zhao LG, Zhang W, Li HL, Gao J, Han LH, et al. Combined impact of known lifestyle factors on Total and cause-specific mortality among Chinese men: a prospective cohort study. Sci Rep. 2017;7(1):5293. https:// doi.org/10.1038/s41598-017-05079-5.

5. Fan X, Cao ZB. Physical activity among Chinese school-aged children: national prevalence estimates from the 2016 physical activity and fitness in China-the youth study. J Sport Health Sci. 2017;6(4):388-94. https://doi.org/1 0.1016/j.jshs.2017.09.006.

6. Shang XW, Liu AL, Zhang Q, Hu XQ, Du SM, Ma J, et al. Report on childhood obesity in China (9): sugar-sweetened beverages consumption and obesity. Biomed Environ Sci. 2012;25(2):125-32. https://doi.org/10.3967/ 0895-3988.2012.02.001

7. Zhang Y, Zhang D, Li X, Ip P, Ho F, Jiang Y, et al. Daily time-use patterns and obesity and mental health among primary school students in Shanghai: a population-based cross-sectional study. Sci Rep. 2017;7(1):16200. https:// doi.org/10.1038/s41598-017-15102-4.

8. Loewen OK, Maximova K, Ekwaru JP, Faught EL, Asbridge M, Ohinmaa A, et al. Lifestyle behavior and mental health in early adolescence. Pediatrics. 2019;143(5):e20183307. https://doi.org/10.1542/peds.2018-3307. 
9. Schuch FB, Vancampfort D, Firth J, Rosenbaum S, Ward PB, Silva ES, et al Ponce De Leon a, Dunn AL, Deslandes AC, fleck MP, Carvalho AF, Stubbs B. physical activity and incident depression: a Meta-analysis of prospective cohort studies. Am J Psychiatry. 2018;175(7):631-48. https://doi.org/10.11 76/appi.ajp.2018.17111194.

10. Korczak DJ, Madigan S, Colasanto M. Children's physical activity and depression: a Meta-analysis. Pediatrics. 2017;139(4):e20162266. https://doi. org/10.1542/peds.2016-2266.

11. Xu H, Sun Y, Wan Y, Zhang S, Xu H, Yang R, et al. Eating pattern and psychological symptoms: a cross-sectional study based on a national large sample of Chinese adolescents. J Affect Disord. 2019;244:155-63. https://doi. org/10.1016/j.jad.2018.10.090

12. Ranum BM, Wichstrøm L, Pallesen S, Falch-Madsen J, Halse M, Steinsbekk S. Association between objectively measured sleep duration and symptoms of psychiatric disorders in middle childhood. JAMA Netw Open. 2019;2(12): e1918281. https://doi.org/10.1001/jamanetworkopen.2019.18281.

13. Busch V, Van Stel HF, Schrijvers AJ, de Leeuw JR. Clustering of health-related behaviors, health outcomes and demographics in Dutch adolescents: a cross-sectional study. BMC Public Health. 2013;13(1):1118. https://doi.org/1 0.1186/1471-2458-13-1118

14. Vermeulen-Smit E, Ten Have M, Van Laar M, De Graaf R. Clustering of health risk behaviours and the relationship with mental disorders. J Affect Disord. 2015;171:111-9. https://doi.org/10.1016/j.jad.2014.09.031.

15. Cheval B, Courvoisier DS, Chanal J. Developmental trajectories of physical activity during elementary school physical education. Prev Med. 2016;87: 170-4. https://doi.org/10.1016/j.ypmed.2016.02.043.

16. Artaud F, Sabia S, Dugravot A, Kivimaki M, Singh-Manoux A, Elbaz A. Trajectories of unhealthy behaviors in midlife and risk of disability at older ages in the Whitehall II cohort study. J Gerontol A Biol Sci Med Sci. 2016; 71(11):1500-6. https://doi.org/10.1093/gerona/glw060.

17. Korhonen T, Kujala UM, Rose RJ, Kaprio J. Physical activity in adolescence as a predictor of alcohol and illicit drug use in early adulthood: a longitudinal population-based twin study. Twin Res Hum Genet. 2009;12(3):261-8. https://doi.org/10.1375/twin.12.3.261.

18. Babore A, Trumello C, Candelori C, Paciello M, Cerniglia L. Depressive symptoms, Self-Esteem and Perceived Parent-Child Relationship in Early Adolescence. Front Psychol. 2016;7:982.

19. Kann L, Kinchen S, Shanklin SL, Flint KH, Kawkins J, Harris WA, et al. Zaza S; Centers for Disease Control and Prevention (CDC). Youth risk behavior surveillance--United States, 2013. MMWR Suppl. 2014;63(4):1-168.

20. Angold A, Costello EJ. The development of a short questionnaire for use in epidemiological studies of depression in children and adolescents. Int J Methods Psychiatr Res. 1995;5(4):237-49.

21. Sun Y, Deng F, Liu Y, Tao FB. Cortisol response to psychosocial stress in Chinese early puberty girls: possible role of depressive symptoms. Biomed Res Int. 2015;2015:781241.

22. Turner N, Joinson C, Peters TJ, Wiles N, Lewis G. Validity of the short mood and feelings questionnaire in late adolescence. Psychol Assess. 2014;26(3): 752-62. https://doi.org/10.1037/a0036572.

23. Costello EJ, Angold A. Scales to assess child and adolescent depression: checklists, screens, and nets. J Am Acad Child Adolesc Psychiatry. 1988;27(6): 726-37. https://doi.org/10.1097/00004583-198811000-00011.

24. Neufeld SAS, Dunn VJ, Jones PB, Croudace TJ, Goodyer IM. Reduction in adolescent depression after contact with mental health services: a longitudinal cohort study in the UK. Lancet Psychiatry. 2017:4(2):120-7. https://doi.org/10.1016/S2215-0366(17)30002-0.

25. Daviss WB, Birmaher B, Melhem NA, Axelson DA, Michaels SM, Brent DA Criterion validity of the mood and feelings questionnaire for depressive episodes in clinic and non-clinic subjects. J Child Psychol Psychiatry. 2006; 47(9):927-34. https://doi.org/10.1111/j.1469-7610.2006.01646.x.

26. Cao FL, Su LY, Cheng PX. Reliability and validity of the mood and feelings questionnaire in Chinese adolescents. Chin J Clin Psychol. 2009;17(4):440-2.

27. Kessler RC, Ustün TB. The world mental health (WMH) survey initiative version of the World Health Organization (WHO) composite international diagnostic interview (CIDI). Int J Methods Psychiatr Res. 2004;13(2):93-121. https://doi.org/10.1002/mpr.168.

28. Wan YH, Hu CL, Hao JH, Sun Y, Tao FB. Deliberate self-harm behaviors in Chinese adolescents and young adults. Eur Child Adolesc Psychiatry. 2011; 20(10):517-25. https://doi.org/10.1007/s00787-011-0213-1.
29. Wan Y, Chen J, Sun Y, Tao F. Impact of childhood abuse on the risk of nonsuicidal self-injury in mainland Chinese adolescents. PLoS One. 2015;10(6): e0131239. https://doi.org/10.1371/journal.pone.0131239.

30. Eaton DK, Kann L, Kinchen S, Shanklin S, Ross J, Hawkins J, et al. Wechsler H; Centers for Disease Control and Prevention (CDC). Youth risk behavior surveillance - United States, 2009. MMWR Surveill Summ. 2010;59(5):1-142.

31. Raudino A, Woodward LJ, Fergusson DM, Horwood L. Childhood conduct problems are associated with increased partnership and parenting difficulties in adulthood. J Abnorm Child Psychol. 2012;40(2):251-63. https:// doi.org/10.1007/s10802-011-9565-8.

32. Meinck F, Cosma AP, Mikton C, Baban A. Psychometric properties of the adverse childhood experiences abuse short form (ACE-ASF) among Romanian high school students. Child Abuse Negl. 2017;72:326-37. https:// doi.org/10.1016/j.chiabu.2017.08.016.

33. Nagin DS, Jones BL, Passos VL, Tremblay RE. Group-based multi-trajectory modeling. Stat Methods Med Res. 2018;27(7):2015-23. https://doi.org/10.11 77/0962280216673085.

34. Landsberg B, Plachta-Danielzik S, Lange D, Johannsen M, Seiberl J, Müller MJ. Clustering of lifestyle factors and association with overweight in adolescents of the Kiel obesity prevention study. Public Health Nutr. 2010; 13(10A):1708-15. https://doi.org/10.1017/S1368980010002260.

35. Wiium N, Breivik K, Wold B. Growth trajectories of health behaviors from adolescence through young adulthood. Int J Environ Res Public Health. 2015;12(11):13711-29. https://doi.org/10.3390/ijerph121113711.

36. Carli V, Hoven CW, Wasserman C, Chiesa F, Guffanti G, Sarchiapone M, et al. A newly identified group of adolescents at "invisible" risk for psychopathology and suicidal behavior: findings from the SEYLE study. World Psychiatry. 2014;13(1):78-86. https://doi.org/10.1002/wps.20088.

37. Poortinga $W$. The prevalence and clustering of four major lifestyle risk factors in an English adult population. Prev Med. 2015;44(2):124-8.

38. Rodelli M, De Bourdeaudhuij I, Dumon E, Portzky G, DeSmet A. Which healthy lifestyle factors are associated with a lower risk of suicidal ideation among adolescents faced with cyberbullying? Prev Med. 2018;113:32-40. https://doi.org/10.1016/j.ypmed.2018.05.002

39. Babic M, Colyvas K, Morgan P, Plotnikoff R, Lonsdale C, Lubans D. Longitudinal associations between recreational screen-time and mental health in Australian adolescents: a cross-lagged panel analysis. J Sci Med Sport. 2017;20(1):e4. https://doi.org/10.1016/j.jsams.2016.12.012.

40. Lubans DR, Smith JJ, Peralta LR, Plotnikoff RC, Okely AD, Salmon J, et al. A school-based intervention incorporating smartphone technology to improve health-related fitness among adolescents: rationale and study protocol for the NEAT and ATLAS 2.0 cluster randomised controlled trial and dissemination study. BMJ Open. 2016;6(6):e010448.

\section{Publisher's Note}

Springer Nature remains neutral with regard to jurisdictional claims in published maps and institutional affiliations.
Ready to submit your research? Choose BMC and benefit from:

- fast, convenient online submission

- thorough peer review by experienced researchers in your field

- rapid publication on acceptance

- support for research data, including large and complex data types

- gold Open Access which fosters wider collaboration and increased citations

- maximum visibility for your research: over $100 \mathrm{M}$ website views per year

At BMC, research is always in progress.

Learn more biomedcentral.com/submission 